Cahiers $d u$ MONDE RUSSE

\section{Cahiers du monde russe}

Russie - Empire russe - Union soviétique et États indépendants

$43 / 4 \mid 2002$

Intellectuels et intelligentsia

\title{
Aleksandr Sergeevič Lavrov, Regentstvo carevny Sof'i Alekseevny
}

André Berelowitch

\section{OpenEdition}

\section{Journals}

Édition électronique

URL : https://journals.openedition.org/monderusse/4009

DOI : 10.4000/monderusse.4009

ISSN : $1777-5388$

Éditeur

Éditions de l'EHESS

\section{Édition imprimée}

Date de publication : 30 décembre 2002

Pagination : 686-688

ISBN : 2-7132-1796-2

ISSN : $1252-6576$

Référence électronique

André Berelowitch, "Aleksandr Sergeevič Lavrov, Regentstvo carevny Sof'i Alekseevny », Cahiers du monde russe [En ligne], 43/4 | 2002, mis en ligne le 17 juin 2009, consulté le 03 septembre 2022. URL http://journals.openedition.org/monderusse/4009; DOI : https://doi.org/10.4000/monderusse.4009

Ce document a été généré automatiquement le 3 septembre 2022

Tous droits réservés 


\title{
Aleksandr Sergeevič Lavrov, Regentstvo carevny Sof'i Alekseevny
}

\author{
André Berelowitch
}

\section{RÉFÉRENCE}

Aleksandr Sergeevič LAVROV, Regentstvo carevny Sof'i Alekseevny. Služiloe obwčestvo i bor'ba za vlast' v verhah Russkogo gosudarstva v 1682-1689 gg. (La régence de la princesse Sophie Alekseevna. La noblesse de service et la lutte pour le pouvoir au sommet de l'État russe, 1682-1689). Moscou, Arheografičeskij Centr, 1999, $300 \mathrm{p}$.

1 Le petit ouvrage, tout à fait remarquable, d'Aleksandr Lavrov traite d'une période brève, mais cruciale pour l'histoire de la Russie moderne : celle où, ayant pris le pouvoir à la faveur d'une sédition des mousquetaires (strel'cy), Sophie tente de résoudre la crise politique et religieuse en modernisant l'État. L'auteur ne cherche pas à présenter une synthèse des connaissances acquises ${ }^{1}$, mais à comprendre les points obscurs qui subsistent dans l'historiographie: comment Sophie s'est emparée du pouvoir (chapitre 1), pourquoi ses réformes ont échoué (chapitre 2), comment s'explique la victoire de Pierre I ${ }^{\text {er }}$ en 1689 (chapitre 3).

2 Ce faisant, il s'attaque au sujet le plus difficile qui soit: la façon dont les luttes de factions qui déchirent la cour, et d'abord la famille régnante, s'inscrivent dans la marche des événements et l'évolution de la société. En effet, les Russes de la fin du XVII siècle expriment le plus souvent leurs opinions politiques non par des écrits ou des prises de position tranchées, mais en se ralliant à des groupes fondés sur la parenté, les alliances matrimoniales, les liens de clientèle. L'analyse politique passe donc par la prosopographie: il s'agit de reconstituer, à travers les nominations, les limogeages, l'absence à telle ou telle cérémonie, les opinions de dizaines, voire de centaines, d'individus (la cour moscovite compte en 1680 près de 6500 personnes). Trop souvent, les historiens se contentent de plaquer, sur un tableau purement descriptif de la cour, des 
constructions arbitraires dictées par les idées en vogue : triomphe de l'aristocratie, ou de la noblesse moyenne, lutte des classes, etc.

3 Tout autre est la méthode employée par Aleksandr Lavrov. Chacune des petites monographies qui composent le livre commence par un exposé de la question, appuyé sur de très solides lectures. L'auteur tire d'un oubli immérité des travaux anciens, ne néglige pas les publications occidentales et s'attache à repérer les failles de l'historiographie traditionnelle. Il entreprend alors de reconstituer les faits, à partir de sources imprimées mais surtout manuscrites, notamment les témoignages des étrangers ${ }^{2}$ et les registres (zapisnye knigi) où le secrétariat de la Guerre notait au jour le jour les décisions des souverains. L'analyse des documents est un modèle de rigueur et de finesse. C'est ainsi que deux mots (on že) suffisent pour affirmer que le procès-verbal de l'interrogatoire de Théodore Šaklovityj a été remanié après coup, afin d'atténuer la culpabilité du prince V.V. Golicyn (p.170), et quelques ratures pour montrer que Šaklovityj est sûr, au début, de l'impunité (p. 173).

4 Jamais cependant l'érudition n'est pratiquée pour elle-même et l'auteur n'oublie pas un instant le but qu'il s'est fixé. Au terme de l'analyse, en une page, parfois moins, il énonce ses conclusions. Ainsi, pour s'en tenir au premier chapitre, les princes Hovanskij n'ont pas essayé de s'emparer du trône, ils ont seulement voulu profiter de leur popularité auprès des mousquetaires pour occuper les premières places à la cour et au gouvernement (p. 47). Ils se sont isolés, par là-même, du reste de la noblesse (p. 24). Loin d'avoir partie liée avec les Hovanskij ou les mousquetaires, c'est au contraire après les avoir éliminés que Sophie peut s'emparer du pouvoir (p. 77).

5 Le bilan de ces recherches est considérable, et notre connaissance de la période 1682-1689 en sort transformée. A. Lavrov montre, de façon convaincante parce que détaillée et réaliste, le mode de fonctionnement des institutions traditionnelles, fondées sur le consensus des élites, à la veille de leur anéantissement. Il fait ressortir le contraste entre les deux crises qui marquent le début et la fin de la période. En 1682, c'est la mobilisation du régiment de la cour et de la cavalerie provinciale qui permet aux proches de Sophie d'éliminer les Hovanskij et de réprimer leurs partisans. C'est aussi le chant du cygne de la noblesse moscovite en tant que force politique active (p.191). En 1689, véritable révolution de palais qui préfigure celles $d u \mathrm{XVIII}^{\mathrm{e}}$ siècle et acte de naissance de l'absolutisme, la faction des Naryškin, largement minoritaire au sein de la noblesse de cour (p. 184-185), l'emporte sur celle des Miloslavskij, qui ne l'est pas moins (p. 89, 96).

Ce livre original, qui renouvelle l'histoire politique de la Russie ancienne, ne va pas cependant sans quelques faiblesses. L'absence d'index et l'abondance des fautes d'impression sont évidemment regrettables. Certains épisodes de la lutte entre les factions adverses font l'objet d'interprétations hésitantes, parce que fondées sur des indices trop fragiles (p. 90-91). A. Lavrov dit (p. 99-100), mais ne souligne peut-être pas assez, que l'effervescence politique de la noblesse à partir de 1682 est la conséquence directe de l'affaiblissement de la monarchie. On ne voit pas comment concilier la « forte activité corporative » de la noblesse lors des états (zemskij sobor) de 1683-1684 (p. 125) avec la soudaine «baisse d'activité » de cette même noblesse, censée expliquer sa défaite finale en 1689 (p.192). On aimerait enfin voir évoquée, sinon résolue, la question fondamentale que suggère la lecture de l'ouvrage : la crise de la fin de siècle est-elle endogène, liée à l'évolution de la société moscovite, ou est-elle exogène, l'occidentalisation progressive de la Russie ayant rendu nécessaire la transformation des structures politiques? 


\section{NOTES}

1. Le lecteur occidental trouvera un tableau d'ensemble des événements dans la biographie détaillée de Sophie par Lindsey Hugues, Sophia, Regent of Russia, 1657-1704, Londres et New Haven, 1990.

2. A. Lavrov a publié en 1996 une édition bilingue commentée de la Relation curieuse et nouvelle de Moscovie de Foy de La Neuville (La Haye, 1698). 